\title{
Ophthalmic endoscope: A novel diagnostic imaging tool
}

\author{
Seemant Raizada*1, Jamal Al Kandari ${ }^{1}$, Khalid Al Sabti ${ }^{2}$ \\ ${ }^{1}$ Vitreo Retinal Unit, Al-Bahar Eye Center, Ibn Sina Hospital; Dasman Diabetes Institute, Kuwait \\ ${ }^{2}$ Kuwait Specialized Eye Center, Kuwait
}

Received: January 4, 2017

Accepted: February 27, 2017 Online Published: March 16, 2017

DOI: $10.5430 /$ ijdi.v4n2p9

URL: https://doi.org/10.5430/ijdi.v4n2p9

\begin{abstract}
The purpose of the study was to evaluate the feasibility of ophthalmic endoscope as a diagnostic tool. This was a prospective, non-comparative, interventional clinical study of 11 consecutive patients who underwent endoscopy-assisted management for ocular pathologies. We used a fused fiber-optic type of endoscope to visualize areas of the eye which were not seen clearly, due to media opacity, through conventional viewing systems like indirect ophthalmoscopy or wide angle viewing system. Eleven cases were enrolled in the study. Five patients underwent endoscopic examination of the fundus prior to penetrating keratoplasty (PKP) or keratoprosthesis. In one out of these 5 cases, PKP was differed due to pale optic nerve. Patient number $6,7 \& 8$ were cases of recurrent vitreous hemorrhage. In these patients, endoscope was used to inspect the sclerotomy from inside and to remove incarcerated vitreous and fibro-vascular membrane. Patient number 9 was a case of poorly dilating pupil undergoing cataract surgery. Endoscope was used in this patient to locate the exact position of haptics of PCIOL. In cases 10 and 11, endoscope was used to localize ciliary sulcus and to document the position of haptics of sclera fixated IOL. Conclusion: The ophthalmic endoscope provides valuable information by illuminating, video recording, and by providing clear view of areas not visible by conventional viewing systems. It can help in management strategies in selected cases.
\end{abstract}

Key Words: Endoscope, Diagnostic tool, Corneal opacity, Penetrating keratoplasty, Recurrent vitreous hemorrhage, Localizing IOL haptics

\section{INTRODUCTION}

The presence of corneal opacity or other media opacities obscure or prevent the view of the retina through conventional viewing systems; and therefore, in such cases, the endoscope assisted vitreoretinal surgery has been claimed to be useful. ${ }^{[1-11]}$ Endoscope is reported to be of use in all the parts of eye e.g. in orbit, ${ }^{[12]}$ nasolacrimal duct obstructions ${ }^{[13,14]}$ glaucoma ${ }^{[15,16]}$ and cataract surgery. ${ }^{[17-19]}$

Diagnostic value of endoscope in ophthalmology has not been much investigated. Nevertheless, there are several re- ports published in peer reviewed journals regarding use of ocular endoscope for diagnostic purposes. There is a report of nasal endoscopy diagnosing a nasolacrimal cyst in one patient. ${ }^{[14]}$ Another diagnostic use is viewing retinal periphery during fluorescein angiography. ${ }^{[20]}$ One study showed importance of diagnostic endoscopy in post mortem examination of eyes to help in ascertaining the cause of death. ${ }^{[21]}$ Endoscope is also reported to be used as a diagnostic tool for the assessment of the safety and vitreous interaction of sustained release intraocular devices. ${ }^{[22]}$ Endoscope has also been

\footnotetext{
*Correspondence: Seemant Raizada, MD, FRCSEd; Email: seemantpolly@gmail.com; Address: Al-Bahar Eye Center, Ibn-Sina Hospital, Safat 13115, Kuwait.
} 
reported to be useful in imaging the ciliary body and iridocorneal angle ${ }^{[23]}$ and viewing from inside and understanding of structural changes in 20G, 25G, and 23G vitrectomy. ${ }^{\text {[24] }}$ Another reported diagnostic use of endoscope is in viewing the ciliary body anatomy and diagnosing the pathology in cases of hypotony. ${ }^{[25]}$

We herein report our findings of using endoscope as a diagnostic imaging tool in planning management strategies in some selected cases with ocular pathologies.

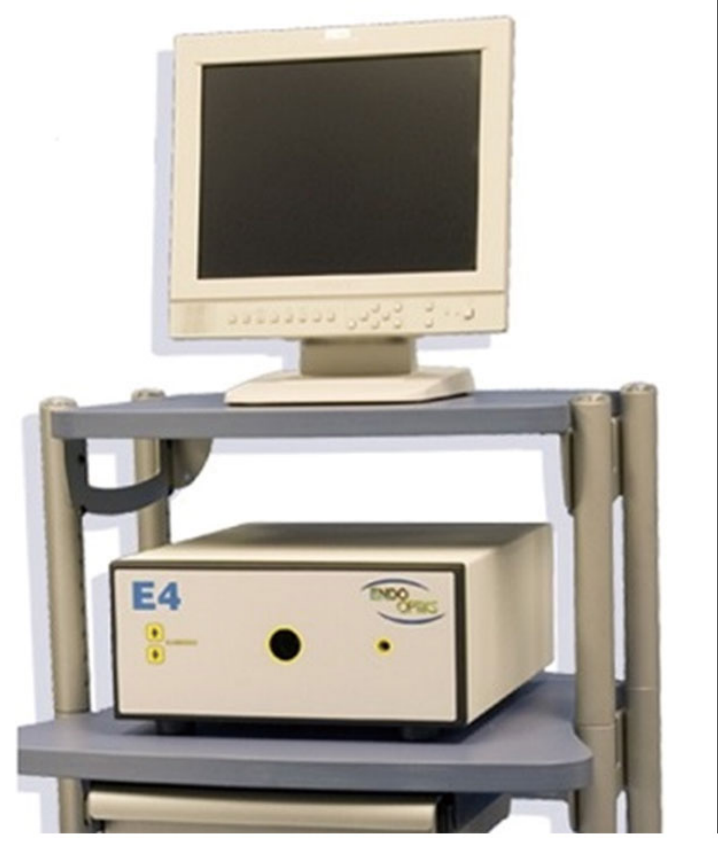

\section{SUBJECTS AND METHODS}

This was a prospective, non-comparative, non-randomized, interventional, clinical study. We include eleven consecutive cases in which the endoscope (E-4 Microprobe, manufactured by Endo-optiks Inc. Little Silver, NJ USA) (see Figure 1) was used as a diagnostic tool. The rationale for the use of endoscope was explained to all patients, and informed consent was obtained. This study was approved by the local ethics committee and institutional review board.

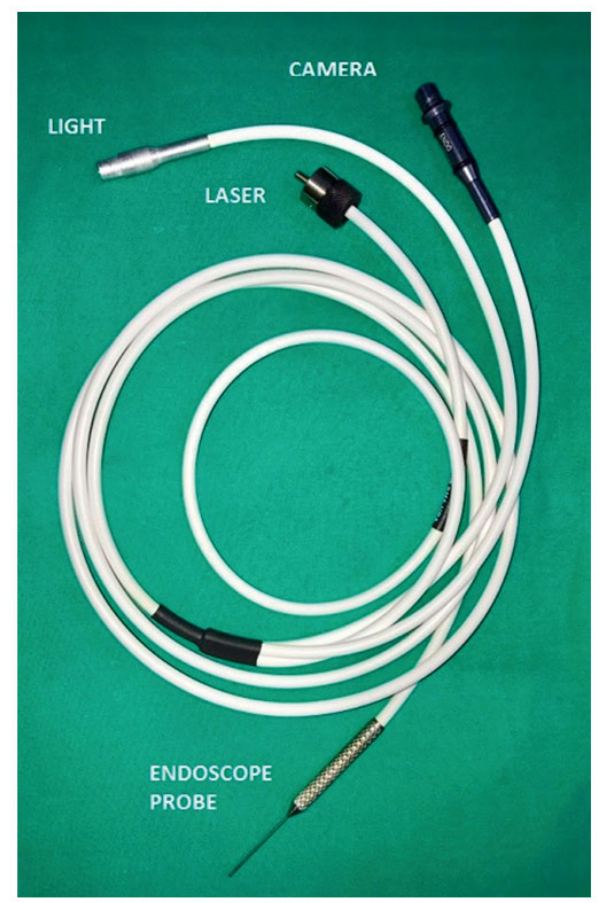

Figure 1. E-4 Microprobe (Endo-optiks Inc. Little Silver, NJ USA)

We used a fused fiber-optic type of endoscope. It is a $0.88 \mathrm{~mm} / 20 \mathrm{G}$ probe. The fused fiber optic technology makes it more flexible, provides a larger field of view and is focused only once before starting the surgery. It is done by adjusting the light source push buttons to obtain a satisfactory video image, and bring the target video image into clear focus by rotating the star wheel on the Video Adapter. The compact endoscopy cabinet houses a 175-watt xenon light source (Visible output 2,200 Lumins; Radiant output 25 watts) and a 10k-pixel CCD camera. This compact unit also creates the opportunity to simultaneously image and to do endolaser. A high-resolution monitor (Sony PVM-14M2MDU) is placed near the surgeon for video display.

All patients had a minimum follow-up of four months after the ocular endoscope procedure to be included in the study. The details of the endoscopic surgery and operative complications were noted. Postoperative findings of visual acuity, intraocular pressure, posterior segment status and ultrasound findings were recorded on case to case basis.

Five cases with corneal opacities (waiting for corneal transplant in 4 cases and for Keratoprosthesis in one case) with indeterminate history of posterior segment pathology, were included in the study. Other indications to use endoscope as a diagnostic tool were, in three cases of recurrent vitreous hemorrhage; in one case to ascertain haptic position of posterior chamber IOL in a patient with semi-dilated pupils; in two cases to ascertain the position of the haptic in sclera fixated IOL. The outcome measured was whether the endoscope helped in the clinical decision making in the management of these patients.

The endoscope probe was inserted in the eye through the pars plana by making a standard 20 gauge sclerotomy incision. In diagnostic endoscopy cases two sclerotomies are made. Irrigating light pipe is used to do partial anterior vitrectomy 
to avoid vitreous traction and incarceration during endoscope insertion and maneuvering. Orientation of the image is ascertained on the screen before inserting the endoscope inside the eye. The endoscope is then directed towards the area of interest $e . g$. in first 5 cases, disc and macula were visually assessed to decide whether penetrating keratoplasty (PKP) would be worthwhile or not. In cases 6,7 , and 8 endoscope was used to examine the peripheral retina and the old sclerotomies from inside to find the cause of recurrent vitreous hemorrhage. In case 9 endoscope was inserted into the anterior chamber of the eye through the corneal entry wound and directed towards the peripheral part of capsular bag to ascertain the position of the haptics. In cases 10 and 11, en- doscope was used to localize the ciliary sulcus and to insert the needle/suture under direct visualization for correct sclera fixation of IOL and to visualize the position of the haptics. At the end of the procedure the periphery of the retina is checked for any iatrogenic tears. We used $20 \mathrm{G}$ endoscope probe hence all the sclorotomies were sutured with $7 / 0$ vicryl at the end of the procedure.

\section{RESULTS}

Eleven consecutive cases in which endoscope were used are being reported in this study. Their demographic characteristics and primary diagnosis are given in Table 1.

Table 1. Patient Demographics, diagnosis and results

\begin{tabular}{|c|c|c|c|c|c|c|c|c|}
\hline $\begin{array}{l}\text { Serial } \\
\mathbf{N}\end{array}$ & Age/sex & Diagnosis & Vision & Procedure & Result & Remark & $\begin{array}{l}\text { Follow Up } \\
\text { (months) }\end{array}$ & $\begin{array}{l}\text { BCVA at last } \\
\text { follow up }\end{array}$ \\
\hline 1 & $60 / \mathrm{M}$ & Silicone oil induced keratopathy & $20 / 400$ & $\begin{array}{l}\text { Diagnostic } \\
\text { endoscopy }\end{array}$ & $\begin{array}{l}\text { Retina attached. Disc } \\
\text { mild pallor }\end{array}$ & Underwent PKP & 11 & $20 / 200$ \\
\hline 2 & $60 / \mathrm{F}$ & $\begin{array}{l}\text { Pseudophakic bullous } \\
\text { keratopathy. High IOP }\end{array}$ & $20 / 600$ & $\begin{array}{l}\text { Diagnostic } \\
\text { endoscopy. ECP }\end{array}$ & $\begin{array}{l}\text { Retina flat. Disc } \\
\text { macula OK. IOP } \\
\text { controlled }\end{array}$ & Underwent PKP & 10 & $20 / 80$ \\
\hline 3 & $74 / \mathrm{F}$ & $\begin{array}{l}\text { ICE. Post PKP graft failure. } \\
\text { High IOP not responded to } \\
\text { transscleral diode. }\end{array}$ & $\begin{array}{l}\text { Hand } \\
\text { movement } \\
\text { close to face. }\end{array}$ & $\begin{array}{l}\text { Diagnostic } \\
\text { endoscopy. ECP }\end{array}$ & $\begin{array}{l}\text { Retina flat. Pale disc. } \\
\text { IOP controlled }\end{array}$ & PKP deferred & 6 & $\begin{array}{l}\text { Hand } \\
\text { movement } \\
\text { close to face }\end{array}$ \\
\hline 4 & $67 / F$ & $\begin{array}{l}\text { Mature senile cataract. Dense } \\
\text { corneal opacity }\end{array}$ & $\begin{array}{l}\text { Hand } \\
\text { movement } \\
\text { close to face }\end{array}$ & $\begin{array}{l}\text { Diagnostic } \\
\text { endoscopy }\end{array}$ & $\begin{array}{l}\text { Retina flat. Disc } \\
\text { macula ok }\end{array}$ & Underwent PKP & 8 & $20 / 40$ \\
\hline 5 & $70 / \mathrm{F}$ & Ocular cicatricial pemphigoid & $20 / 500$ & $\begin{array}{l}\text { Diagnostic } \\
\text { endoscopy }\end{array}$ & $\begin{array}{l}\text { Retina flat. Disc, } \\
\text { macula OK }\end{array}$ & $\begin{array}{l}\text { Keratoprosthesis } \\
\text { implanted }\end{array}$ & 6 & $20 / 70$ \\
\hline 6 & $63 / \mathrm{M}$ & Recurrent vitreous hemorrhage & $20 / 500$ & $\begin{array}{l}\text { Diagnostic } \\
\text { endoscopy }\end{array}$ & $\begin{array}{l}\text { Showing vitreous } \\
\text { incarceration Retina } \\
\text { flat }\end{array}$ & $\begin{array}{l}\text { Endoscope mediated } \\
\text { vitreous removal and } \\
\text { endolaser }\end{array}$ & 11 & $20 / 300$ \\
\hline 8 & $69 / \mathrm{M}$ & Recurrent vitreous hemorrhage & $20 / 400$ & $\begin{array}{l}\text { Diagnostic } \\
\text { endoscopy }\end{array}$ & $\begin{array}{l}\text { FVM under old } \\
\text { sclerotomy. Retina flat }\end{array}$ & $\begin{array}{l}\text { Endoscope mediated } \\
\text { FVM removal and } \\
\text { endolaser }\end{array}$ & 7 & $20 / 80$ \\
\hline 9 & $55 / \mathrm{M}$ & Small pupil & $20 / 80$ & $\begin{array}{l}\text { Endoscope used } \\
\text { to see position of } \\
\text { haptics of IOL }\end{array}$ & $\begin{array}{l}\text { IOL haptic out of the } \\
\text { capsular bag }\end{array}$ & $\begin{array}{l}\text { IOL dialed in the } \\
\text { capsular bag }\end{array}$ & 4 & $20 / 25$ \\
\hline 10 & $35 / \mathrm{M}$ & $\begin{array}{l}\text { Traumatic dislocation of the } \\
\text { crystalline lens }\end{array}$ & $20 / 400$ & $\begin{array}{l}\text { Endoscope to see } \\
\text { the position of the } \\
\text { position of } \\
\text { haptics }\end{array}$ & $\begin{array}{l}\text { IOL correctly sutured } \\
\text { in the sulcus with the } \\
\text { help of endoscope }\end{array}$ & IOL stable & 5 & $20 / 40$ \\
\hline 11 & $40 / \mathrm{M}$ & $\begin{array}{l}\text { Subluxated IOL after } \\
\text { complicated } \\
\text { phacoemulsification }\end{array}$ & $20 / 70$ & $\begin{array}{l}\text { Endoscope to see } \\
\text { the position of the } \\
\text { position of } \\
\text { haptics }\end{array}$ & $\begin{array}{l}\text { IOL correctly sutured } \\
\text { in the sulcus with the } \\
\text { help of endoscope }\end{array}$ & IOL stable & 4 & $20 / 30$ \\
\hline
\end{tabular}

Note. I.C.E.- Irido corneal endothelial syndrome; PKP - Penetrating keratoplasty ; ECP - Endoscopic Cyclo-photocoagulation; IOP - Intra Ocular Pressure; IOL - Intraocular lens; FVM - Fibrovascular Membrane.

Cases 1 to 5 were having opaque cornea in the affected eye and were waiting for PKP or keratoprosthesis. However, the status of the optic nerve and the retina in these cases were unknown. B-scan ultrasonography can reveal the status of attached/detached retina but cannot document the state of macula or optic nerve head. Hence, the endoscope was used for diagnostic purposes to visually evaluate the health of the disc and macula.
Case 1 was diagnosed as silicone oil induced keratopathy following vitrectomy with silicone oil injection for complex retinal detachment in the left eye. The keratopathy persisted after removal of silicone oil and he was referred to retina clinic for assessment of posterior segment prior to PKP. Endoscopic view revealed flat retina and healthy optic disc. The patient underwent a corneal transplant surgery with satisfactory results. 
Case 2 was a 60-year-old lady who developed pseudophakic bullous keratopathy in left eye with intractable high intraocular pressure (IOP) for 2 years not responding to maximal anti glaucoma treatment. She underwent trans-scleral cyclodiode laser after which her IOP remained under control Since she had high IOP for a prolonged period of time, she was referred to the retina clinic for the assessment of optic nerve head prior to PKP. Endoscopy revealed reasonably healthy disc and macula. She was then referred back to cornea unit for PKP.

Case 3 was a case of Iridocorneal endothelial (ICE) syndrome. She underwent PKP with cataract extraction and PCIOL implantation in right eye. Postoperatively she developed high IOP and corneal graft edema. Her IOP could not be controlled on maximal anti-glaucoma therapy, so she underwent trans-scleral cyclodiode laser therapy. Despite cyclodiode laser, her IOP remained high. She was referred to retina clinic for assessment of posterior segment prior to second PKP. Endoscopic examination revealed near total cupping of optic nerve head with no healthy rim (see Figure 2 ). Due to expected poor prognosis, PKP was deferred in this case.

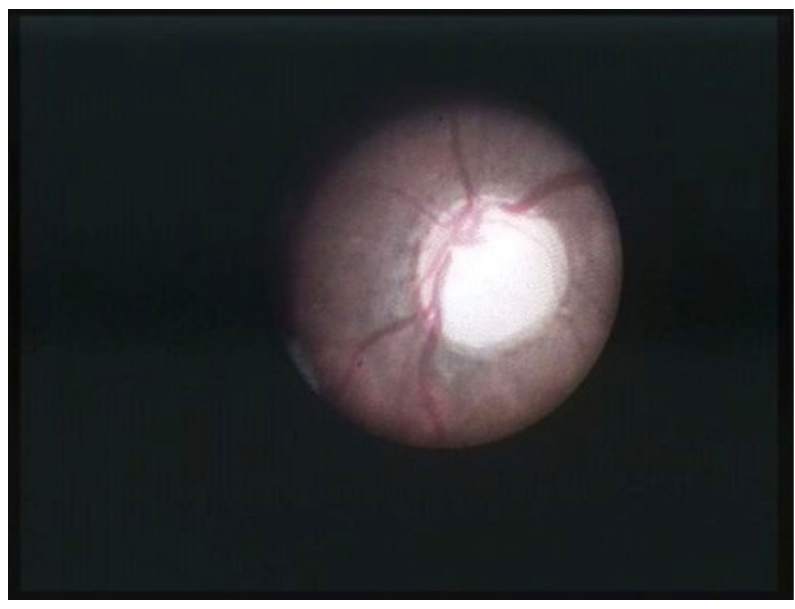

Figure 2. Endoscopic view of optic nerve head in case number-3, shows near total cupping

Case 4 was a 67-year-old lady with significant corneal opacity and cataract. She was referred to retina clinic for posterior segment assessment prior to combined PKP and cataract surgery. She was seen in cornea clinic for the first time and there was no previous records regarding her optic nerve health or retinal status. Because macular function tests were inconclusive in her case, diagnostic endoscopy was done, which showed healthy disc and macula. She was referred back to cornea unit for PKP.

Case 5 was a 70-year-old lady, a known case of ocular cicatricial pemphigoid. She underwent successful keratoprosthesis
Type I implantation in right eye followed by vision improvement to 20/400. To assess the feasibility of keratoprosthesis implantation in left eye, she underwent diagnostic endoscopy to visually evaluate the status of retina, macula and optic disc prior to surgery. Direct visualization by endoscope revealed healthy macula and optic disc. Keratoprosthesis Type I was implanted in left eye and the vision improved to 20/70 with correction after surgery.

Cases 6, 7 and 8 were cases of recurrent vitreous hemorrhage. All these 3 cases were operated few years ago with 20 gauge vitrectomy. Case 6 was a diabetic lady with recurrent vitreous hemorrhage. She underwent pars plana vitrectomy twice for vitreous hemorrhage but she developed vitreous hemorrhage again. Endoscope was used in this case to examine the sclerotomy site from inside. No membranes were seen under the sclerotomy site but presence of vitreous attachment and incarceration was seen at the sclerotomy site from inside. The vitreous was shaved off assisted by endoscopic visualization. On her last visit her right eye vision was 20/400. Fundus examination showed clear media and flat retina. In cases 7 and 8, examination via endoscope revealed fibro-vascular proliferation (see Figure 3). These membranes were surgically removed using endoscopic visualization.

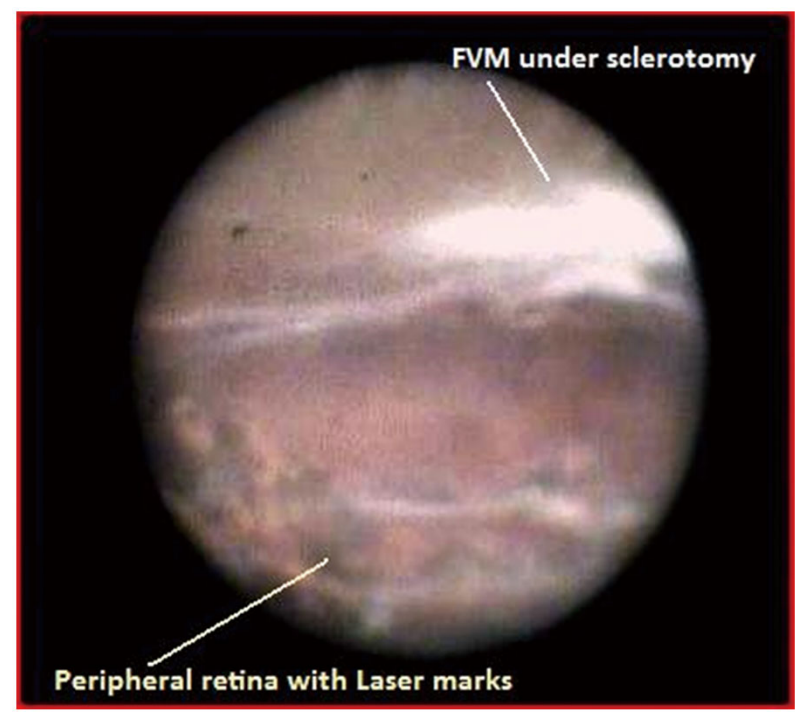

Figure 3. Endoscopic view of the case number-7, shows fibro-vascular membrane (FVM) on the underside of the previous sclerotomy site

Case 9 was a case of cataract with annular arcus senilis. The phacoemulsification was done but at the end of the surgery pupil started to constrict. This made the view of the peripheral anterior chamber difficult. After insertion of IOL, we were not sure whether both haptics were in the bag due to poor peripheral view of the anterior chamber. Endoscope 
was used as a diagnostic imaging tool to assess the position of haptics. The inferior haptic was found to be out of the bag (see Figure 4) and was redialed in the bag. In Case 10 and 11 , endoscopic view was used to localize the ciliary sulcus to place the sutures correctly in the sulcus and to assure that the IOL haptics were in sulcus.

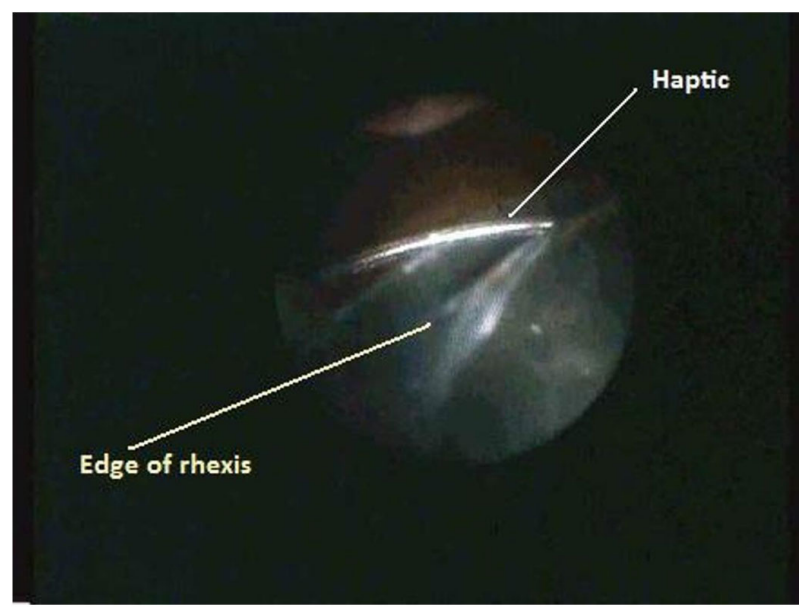

Figure 4. Endoscopic view of the case number-9, shows one IOL haptic out of the capsular bag

\section{DiscusSion}

Ocular endoscope is a relatively new and often overlooked instrument in the armamentarium of an ophthalmologist. Recent technological advancements have increased the number of indications for endoscopy. In present study we discuss the diagnostic utility of ocular endoscope.

In our part of the world eye donations are not common hence corneas are precious. It would not be wise to do a penetrating keratoplasty in a case where visual prognosis is poor due to pathology of disc and/or of macula. Out of 5 patients assessed before PKP, 4 patients went ahead PKP in separate surgical appointment date. In case 3 PKP was postponed due to disc pallor.

Many tests are available to assess macular function. Simple tests such as light projection, color discrimination, and twopoint discrimination cannot provide adequate information about macular function. ${ }^{[26]}$ The Maddox rod (with limitations), trans-illuminated Amsler grid, and various entoptic phenomena (Purkinje vascular phenomenon, foveal chagrin, Haidinger's brushes, and blue field phenomenon) are available as qualitative subjective tests. ${ }^{[26]}$ Maxwellian view systems with pinhole aperture (potential acuity meter PAM) and the interferometers (retinometer, visometer, SITE-IRAS interferometer) provide quantitative subjective methods. The flash VECP is primarily a qualitative objective test that allows semiquantitative acuity prediction under special conditions

Published by Sciedu Press (unilateral opacities). Newer objective test developments are pattern VECP and pattern ERG elicited by interferometric stimulation, speckle VECP and focal ERG. But several easily recognizable clinical conditions make even the interferometer test also unreliable. ${ }^{[27]}$ In our cases newer conventional macular function tests could have been used but our center is not equipped with VECP and interferometer. Since we are using endoscope in selected vitreo-retinal cases and had access to endoscope in operating room, we felt that direct visualization would be helpful. We know that endoscopic examination cannot be treated as an absolute diagnostic test; this was a pilot study to expand the diagnostic uses of endoscope. Endoscope is useful in cases with macular lesions like macular holes or cysts, geographic atrophy of the pigment epithelium and optic nerve head lesions like atrophy, pallor and cupping. B-scan ultrasound is not helpful in these cases. In these cases due to media opacity direct visualization, fluorescein angiography or optical coherence topography is not possible. Here we would like to emphasize on the point that in our hospital endoscopic examination of the fundus is not carried out on all the cases for PKP prior to surgery. Introducing the endoscope through a sclerotomy has its own potential surgical complications like vitreous hemorrhage, retinal detachment or even endophthalmitis. However, none of our cases developed any complications.

Cases 6, 7 and 8 were patients of recurrent vitreous hemorrhage. It has been reported that vitreous incarceration, anterior hyaloidal fibrovascular proliferation and fibrovascular ingrowth can be a cause of recurrent vitreous hemorrhage after primary vitrectomy done for complications of diabetic retinopathy. ${ }^{[28,29]}$ Bhende $\mathrm{M}$ et al. ${ }^{[28]}$ reported vitreous incarceration detected by ultrasound biomicroscopy in upto $18 \%$ in cases of recurrent vitreous hemorrhage. Hershbergers et al. ${ }^{[29]}$ reported fibrovascular ingrowth seen by ultrasound biomicroscopy in upto $58 \%$ of cases in their series. We diagnosed the offending pathology in our cases and were also able to remove it at same time using endoscope assisted pars plana vitrectomy. In case 9, endoscope was used as an imaging tool to locate the position of haptics. Hence we avoided extra procedures like iris hook placement and decreased the time and effort in the surgery. In case 10 and 11 endoscope was used, intra-operatively, to place sutures in the sulcus and to see the exact position of the haptics. It is well known that placement of haptics and sutures correctly in the ciliary sulcus promote attachment of scar tissue which in turn enhances the long term stability of sulcus fixated lens. ${ }^{[30]}$ It is difficult to place sutures in the ciliary sulcus for sclera fixation of IOL due to lack of visual control by surgeon. Postoperatively UBM has been used in some studies to assess the position of haptics in relation to iris base, ciliary sulcus, pars plicata 
and pars plana. In one study, it was reported that haptics were in sulcus in only $24 \%$ cases. ${ }^{[31]}$ In another UBM study of haptics in trans sclera fixated IOL, it was reported that correctly placed haptics was present in 33\% cases; where as $50 \%$ were located posterior to the sulcus and $17 \%$ were placed anterior to the sulcus. ${ }^{[32]}$ Various methods for ciliary sulcus localization have been used and are reported in literature $e g$. , transillumination with endo-illuminator ${ }^{[31]}$ and mirror needle holder ${ }^{[33]}$ With transillumination technique of localization of ciliary sulcus, haptic placement in sulcus improved to $64 \%$. Another study on use of endoscope in scleral fixation of posterior chamber intraocular lens in pediatric age group suggests that endoscopic-assisted sclera fixation in children is a safe and effective technique that may reduce surgical complications in transscleral sulcus suturing of IOLs and helps the surgeon identify precisely the haptic positions, which may reduce the incidence of iris root and ciliary body damage. ${ }^{[34]}$ Needle penetration under direct vision by the aid of the endoscope also facilitates proper trimming of any vitreous bands at the haptic sites intraoperatively. Ophthalmic micro-endoscope also allows proper examination of the retinal periphery, that might help in lowering the rates of retinal complications like missed peripheral retinal tears. Endoscope guided suture placement was done in our cases for exact placement of haptics in the sulcus. Ophthalmic micro-endoscope is one of the easiest and most practical methods of ciliary sulcus localization intra-operatively and direct visualization of haptics in sulcus fixated IOL surgery.

\section{Conclusion}

Ophthalmic micro-endoscope allows visualization of structures that are not routinely accessible through standard viewing in cases of opaque media, such as the anterior chamber angle, inside capsular bag, retro-iridial space, the ciliary body/processes, the ciliary sulcus, and the posterior segment details along with anterior retina. The disadvantages of endoscopy apart from inherent surgical complications are that it is expensive and has a steep learning curve. The surgeon has to get used to the image on the monitor, in terms of focus and depth perception. We are using a semi-disposable endoscope probe that can be used for approximately ten cases after re-sterilization. Newer endoscope probes which can be inserted through $23 \mathrm{G}$ sclerotomies, and with better optics will make it easier to use.

The present study enumerates few diagnostic uses of ocular endoscope. We feel that full potential of ocular endoscope is not tapped still. It is much underrated and under-utilized tool. Multicentre and wider use of endoscope will probably find more innovative use for this instrument.

\section{CONFlicts OF InTEREST Disclosure}

The authors have declared no conflicts of interest.

\section{REFERENCES}

[1] Thorpe HE. Ocular endoscope: Instrument for removal of intravitreous nonmagnetic foreign bodies. Trans Am. Acad Ophthalmol Otolaryngol. 1934; 39: 422.

[2] Norris JL, Cleasby GW, Nakanishi AS, et al. Intraocular endoscopic surgery. Am J Ophthalmology. 1981; 91: 603-606. https : //doi.org/10.1016/0002-9394(81)90058-1

[3] Leon CS, Leon JA. Micro endoscopic ocular surgery: a new intraoperative, diagnostic and therapeutic strategy I: endoscopic equipment/methodology applied to cataract surgery with intra ocular lens implantation. J. Cataract Refract Surgery. 1991; 17: 568-572. https ://doi.org/10.1016/S0886-3350(13)81042-5

[4] Leon CS, Leon JA. Micro endoscopic ocular surgery: a new intraoperative, diagnostic and therapeutic strategy II: preliminary results from the study of glaucomatous eyes. J. Cataract Refract Surgery. 1991; 17: 573-576. https://doi .org/10.1016/S0886-3350(13) 810 43-7

[5] Faude F, Wiedemann P. Vitreoretinal endoscope for the assessment of the peripheral retina and the ciliary body after large retinectomies in severe anterior PVR. International Ophthalmology. 2004; 25: 53-56. PMid:15085977 https://doi.org/10.1023/B: INTE. 0000018 $550.36179 .9 \mathrm{e}$

[6] Ciardella AP, Fisher YL, Carvalho C, et al. Endoscopic vitreoretinal surgery for complicated proliferative diabetic retinopathy. Retina.
2001; 21: 20-27. PMid:11217925 https://doi.org/10.1097/ 00006982-200102000-00004

[7] Koch FH, Quiroz-Mercado H, Hattenbach LO, et al. Pigment epithelium endoscopic laser surgery for treatment of choroidal neovascularization. Ophthalmologica. 2004; 218(3): 162-175. PMid:15103212 https://doi.org/10.1159/000076840

[8] Boscher C, Lebuisson DA, Lean JS, et al. Vitrectomy with endoscopy for management of retained lens fragment and/or posteriorly dislocated intraocular lens. Graefes Arch Clin Exp Ophthalmol. 1998; 236(2): 115-121. PMid:9498122 https ://doi .org/10.1007/s0 04170050051

[9] Sabti KA, Raizada S, Kandari JA, et al. Application of endoscopy in vitreo retinal surgery. Retina. 2008; 28(1): 159-66. PMid:18185155 https://doi.org/10.1097/IAE.0b013e3181574681

[10] Koch FH, Luloh KP, Augustin AJ, et al. Subretinal microsurgery with gradient index endoscopes. Ophthalmologica. 1997; 211(5): 283-287. PMid:9286802 https://doi .org/10.1159/000310809

[11] Volkov VV, Danilov AV, Vassin LN, et al. Flexible endoscopes. Ophthalmoendoscopic techniques and case reports. Arch Ophthalmol. 1990; 108(7): 956-7. PMid:2369355 https://doi.org/10.100 1/archopht. 1990.01070090058039

[12] Cheong EC, Chen CT, Chen YR. Endoscopic management of orbital fractures. Facial Plast Surg. 2009; 25(1): 8-16. PMid:19206023 https://doi.org/10.1055/s-0028-1112226 
[13] Poublon RM, de Roon Hertoge K. Endoscopic-assisted reconstructive surgery of the lacrimal duct. Clin Plast Surg. 2009; 36(3): 399405. PMid:19505610 https://doi.org/10.1016/j.cps. 2009 .02 .002

[14] Cavazza S, Laffi GL, Lodi L, et al. Congenital dacryocystocele: Diagnosis and treatment. Acta Otorhinolaryngoi Ital. 2008; 28(6): 298-301. PMid:19205594

[15] Valmaggia C, De Smet M. Endoscopic laser coagulation of the ciliary processes in patients with severe chronic glaucoma. Klin Monbl Augenheilkd. 2004; 221(5): 343-6. PMid:15162276 https: //doi.org/10.1055/s-2004-812870

[16] Jacobi PC, Dietlein TS, Krieglstein GK. Microendoscopic trabecular surgery in glaucoma management. Ophthalmology. 1999; 106(3): 538-544. https://doi.org/10.1016/S0161-6420(99) 90113 $-6$

[17] Uka J, Minamoto A, Hirayama T, et al. Endoscope aided cataract surgery in corneal opacity associated with aniridia. J Cataract Refract Surg. 2005; 31(7): 1455-6. PMid:16105626 https : //doi .org/10 $.1016 / j$.jcrs. 2005.05.015

[18] Henderson BA, Ali R, Kim JY, et al. Using endoscopy to teach cataract surgery. J Cataract Refract Surg. 2006; 32(10): 1606-10. PMid:17010854 https://doi.org/10.1016/j.jcrs.2006.04 .034

[19] Khalid S, Raizada S, Abduljalil T. Cataract surgery assisted by anterior endoscopy. Br J Ophthalmol. 2009; 93(4): 531-4. PMid:19151011 https://doi.org/10.1136/bjo.2008.14990 6

[20] Terasaki H, Miyake Y, Mori M, et al. FFA of extreme peripheral retina and rubeosis iridis in proliferative diabetic retinopathy. Retina. 1999; 19(4); 302-308. PMid:10458295 https ://doi .org/10 . 109 7/00006982-199919040-00007

[21] Davis NL, Wetli CV, Shakin JL. The retina in forensic medicine: applications of ophthalmic endoscopy: the first 100 cases. Am J Forensic Med Pathol. 2006; 27(1): 1-10. PMid:16501341 https: //doi.org/10.1097/01.paf.0000201102.03778.65

[22] Koch FH, Gümbel HO, Hattenbach LO, et al. Intravitreal visualization of intraocular ganciclovir devices: Improved long term treatment of CMV retinitis. Klin Monbl Augenheilkd. 1999; 214: 107-111. PMid:10218205 https://doi.org/10.1055/s-2008-1034759

[23] Guyomard JL, Rosolen SG, Paques M, et al. A low cost and simple imaging technique of the anterior and posterior segments: eye fundus, ciliary bodies, iridocorneal angle. Invest Ophthalmol Vis Sci. 2008;
49(11): 5168-74. PMid:18539931 https://doi.org/10.1167/ iovs. $07-1340$

[24] Nagpal M, Wartikar S, Nagpal K. Comparison of clinical outcomes and wound dynamics of sclerotomy ports of 20,25, and 23 gauge vitrectomy. Retina. 2009; 29(2): 225-31. PMid:19202426 https://doi.org/10.1097/IAE.0b013e3181934908

[25] Hammer ME, Grizzard WS. Endoscopy for evaluation and treatment of the ciliary body in hypotony. Retina. 2003; 23(1): 30-6. https://doi.org/10.1097/00006982-200302000-00005

[26] Lachenmayr B. Predicting visual acuity in media opacities and uncorrectable refractive errors. Assessing so-called "retinal visual acuity". Fortschr Ophthalmol. 1990; 87 Suppl: S118-137. PMid:2083891

[27] Faulkner W. Laser interferometric prediction of postoperative visual acuity in patients with cataracts. Am J Ophthalmol. 1983; 95(5): 626636. https://doi.org/10.1016/0002-9394(83)90381-1

[28] Bhende M, Agraharam SG, Gopal L, et al. Ultrasound biomicroscopy of sclerotomy sites after pars plana vitrectomy for diabetic vitreous hemorrhage. Ophthalmology. 2000; 107(9): 1729-1736. https ://doi.org/10.1016/S0161-6420(00) 00213-X

[29] Hershberger VS, Augsburger JJ, Hutchins RK, et al. Fibrovascular ingrowth at sclerotomy site in vitrectomized diabetic eyes with recurrent vitreous hemorrhage: Ultrasound biomicroscopy findings. Ophthalmology. 2004; 111(6): 1215-1221. PMid:15177974 https://doi.org/10.1016/j.ophtha.2003.08.043

[30] Price MO, Price FW Jr, Werner L, et al. Late dislocation of scleralsutured posterior chamber intraocular lenses. J Cataract Refract Surg. 2005; 31(7): 1320-1326. PMid:16105601 https://doi.org/10.1 $016 / j \cdot j$ crs .2004 .12 .060

[31] Alp MN, Buyuktortop N, Hosal BM, et al. Ultrasound biomicroscopic evaluation of the efficacy of a transillumination technique for ciliary sulcus localization in transscleral fixation of posterior chamber intraocular lenses. J cataract Refract Surg. 2009; 35(2): 291-6. PMid:19185245 https://doi.org/10.1016/j.jcrs.2008.10 .045

[32] Stiener A, Steinhorst UH, Steiner M, et al. Ultrasound biomicroscopy for localization of artificial lens haptics after trans-scleral suture fixation. Ophthalmologe. 1997; 94(1): 41-4.

[33] Tsai JC, Rowsey JJ, Fouraker BD, et al. Use of mirror needle holder with transsclerally sutured posterior chamber intraocular lenses. Ophthalmic Surg Lasers. 1996; 27(8): 720-4. PMid:8858641

[34] El Gendy HA, Khalil HE, Haroun HE, et al. Endoscopic assisted Scleral Fixated IOL in Management of Secondary Aphakia in Children. J Ophthalmol. 2016. https://doi .org/10.1155/2016/8501842 